\title{
Post-Occupancy Evaluation of Indoor Environmental Quality in a nZEB sport hall in a Mediterranean climate.
}

\author{
Joana Ortiz ${ }^{1}$, Maria L. Gonzalez Matterson ${ }^{1}$, Paolo Taddeo ${ }^{1}$ and Jaume Salom ${ }^{1 *}$ \\ ${ }^{1}$ Catalonia Institute for Energy Research - IREC, Energy Efficiency in Systems, Buildings and Communities - ECOS group, Jardins de \\ les Dones de Negre 1, 2a 08930 Sant Adrià de Besòs, Barcelona, Spain
}

\begin{abstract}
The aim of the present work is to evaluate the environmental comfort of the users of a new nZEB sport hall located in Tarragona, Spain, through a Post Occupancy Evaluation. The study is composed by two phases of measurements where the visual comfort, the thermal comfort and the air quality are evaluated. The first monitoring campaign is focused on a detailed visual comfort evaluation under daylight conditions, done on July 28th, 2017. The second monitoring campaign is focused on the thermal comfort and the air quality and was performed during the Mediterranean Olympic Games from June 19th to July 1st of 2018. Moreover, around 140 of surveys are done to the audience to compare the calculated comfort parameters with the perception of the users. The results of the Post Occupancy Evaluation are satisfactory, obtaining good comfort indexes and demonstrating a good perception by the users.
\end{abstract}

\section{Introduction}

At the end of 2018, all public buildings should be nearly Zero Energy Buildings (nZEB) according to the Energy Performance of Buildings Directive [1]. An important task is to perform monitoring campaigns to ensure their initial design assumptions and also to guarantee comfortable conditions for the users. To this aim, the Post Occupancy Evaluation (POE) has the purpose of evaluating the current behaviour of the building and identifying possible measures to improve its operation. This paper summarizes the POE of a new nZEB sport hall located in Tarragona, Spain.

\section{Case study}

The case study is the Catalunya Sports Hall - Palau d'Esports de Catalunya (Fig. 1), which was built to host the handball competitions during the XVIII Mediterranean Games in 2018. The building was designed by Barceló Balanzó arquitectes + AIA Salazar Navarro, and promoted to be a nZEB sports facility by the Consell Català de l'Esport, Secretaria General de 1'Esport, Generalitat of Catalunya [2].

\section{1 Building characteristics}

The Catalunya Sports Hall is located in the Mediterranean Ring in Campclar, Tarragona. The oval floor plan is longitudinally oriented North-South and the total gross area is $10,822 \mathrm{~m}^{2}$ with a maximum height of $15 \mathrm{~m}$. The central playing area with $1,920 \mathrm{~m}^{2}$ is in the underground level $(-4.00 \mathrm{~m})$, and allows the layout of up to 3 a-side football pitches. Around the court, the 3 levels of the building are organized $(-4.00 ;+0.00$ and +3.35 ) with a seating capacity of 5,000 spectators.

The structure combines reinforced concrete for pillars and slabs, and steel roof trusses. The metallic roof is slightly curved with a central skylight of $12 \mathrm{~m}$ width and $48 \mathrm{~m}$ length, symmetrically placed in the centre of the playing area. The roof and the façade are covered with a ceramic system. The façade is organized in 3 levels. The fenestration varies its glazing material and the brise-soleil (shading devices), modifying their spacing and orientation to improve the sun protection.

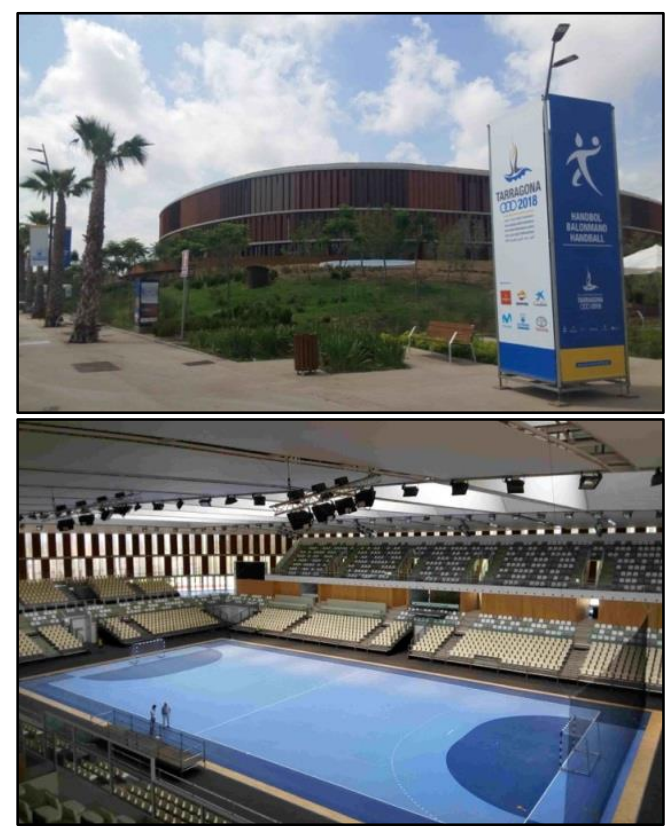

Fig. 1. Images of the premises (top) and the inside (bottom) of the Catalunya Sports Palace.

\footnotetext{
* Corresponding author: jsalom@irec.cat
} 
The main HVAC system is composed by a condensing boiler to cover the heating needs, and two air-to-water heat pumps to provide the cooling demand. The heating and cooling production is used by four air handler units to regulate the air according to the court and the grandstand needs, and provide fresh air to the sport hall, using a $\mathrm{CO} 2$ sensor for regulation. The operation conditions during the 2nd monitoring campaign are configured with a setpoint of $22-23^{\circ} \mathrm{C}$ of air return temperature.

\subsubsection{Skylight optimization}

During the design project, the skylight of $576 \mathrm{~m}^{2}$ was optimized with the aim to provide natural light to the playing area and the visual comfort conditions for the building's users by dynamic daylight simulations [2]. As a result, the skylight features are the following (Fig. 2):

- the glazing is a translucent polypropylene surface with a 0.20 coefficient for visible light transmission;

- the continuous micro-perforated white fabric that covers all the ceiling, creating a sloped shape between the translucent (skylight) and opaque horizontal surfaces (structure);

- the vertical baffles, coated with the same material of ceiling (micro-perforated white fabric), are placed to increase daylight diffusion and for keeping out of sight the skylight openings for users.

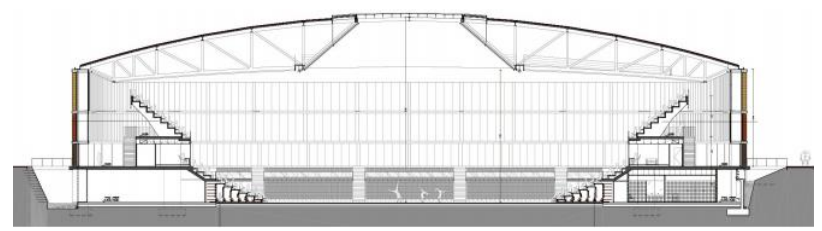

Fig. 2. Cross section (towards the South) of the Catalunya Sports Palace.

\section{Methodology}

The study is composed by two phases of measurements: the $1^{\text {st }}$ monitoring campaign is focused on the visual comfort assessment, and the $2^{\text {nd }}$ campaign is for the thermal comfort, the air quality and audience environmental comfort survey evaluation.

\subsection{Monitoring visual comfort: $1^{\text {st }}$ campaign}

The first monitoring campaign, done on July 28th, 2017, is focused on a detailed visual comfort assessment under daylight conditions [3], performing lighting quantity and quality evaluation [4]. These measurements were carried out in the last phase of the construction works of the sport hall and before the realisation of the Games.

In order to assess the visual comfort of users [5], horizontal illuminance (Eh) measures and High Dynamic Range Images (HDRIs) are obtained under daylighting. The measurements conditions are shown in Table 1

\subsubsection{Horizontal illuminance levels}

For the $\mathrm{E}_{\mathrm{h}}$ at $+1.10 \mathrm{~m}$ level, an orthogonal grid is used (see Fig. 3) covering the total playing area with 117 spots measurements with rows (1 to 9: $4 \mathrm{~m}$ spacing) and columns (A to $\mathrm{M}$ : $5 \mathrm{~m}$ spacing). As a reference value, the outdoor $E_{h}$ is registered at the same time with a luxmeter located on the roof and without obstructions (from $91,1001 \mathrm{x}$ at $11: 25 \mathrm{~h}$ to $99,8001 \mathrm{x}$ at $12: 05 \mathrm{~h}$ ).

Table 1. Measurement conditions during the visual comfort measurements and surveys.

\begin{tabular}{|c|c|c|c|c|}
\hline $\begin{array}{c}\text { Data } \\
\text { obtained }\end{array}$ & Date & Time & Sky & Lights \\
\hline $\mathrm{E}_{\mathrm{h}}$ & $28 / 07 / 2017$ & $\begin{array}{c}\text { Start 11:25 } \\
\text { End: 12:05 }\end{array}$ & Clear & off \\
\hline $\begin{array}{c}\text { HDRI } \\
\text { L }\end{array}$ & $28 / 07 / 2017$ & $\begin{array}{c}\text { Start: 13:00 } \\
\text { End: } 15: 05\end{array}$ & Clear & off \\
\hline
\end{tabular}

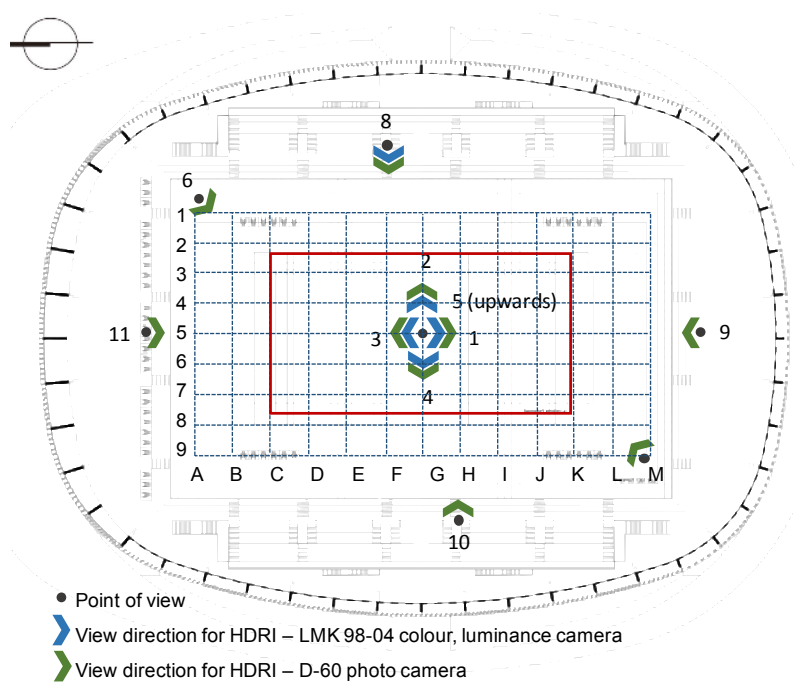

Fig. 3. Drawing of the Catalunya Sports Hall $(+3.35)$ with sensor positions for illuminance (lux-meter), viewpoints and directions for HDRI.

\subsubsection{HDRI and Luminance survey}

The HDR images are taken with a luminance camera (Charged Couple Device-CCD). The sensors and software used for the visual comfort assessment are described in Table 2. Different shots at +1.55 level are taken in order to cover the visual field of players and audience (shown in Fig. 3). For the players, the points of view are set on the centre of the court, towards the main 5 directions of view: both sides, back, front and upwards (ceiling). For the audience, these are placed in the seating area towards the court. The images resulting of 640x480 pixels with luminance (L) values (scale: 0 $85,000 \mathrm{~cd} / \mathrm{m}^{2}$ ), that will be displayed in false colour. For the HDRI luminances and glare assessments [5], three 3 regions of interest are established in the Visual Field of View (FOV) $[1,2]$ :

- Region 1: focus $\left(2^{\circ}\right)$,

- Region 2: immediate surrounding $\left(30^{\circ}\right)$, and 
- Region 3: far surrounding and background $\left(60^{\circ}-90^{\circ}\right)$, including the total field of view.

For the visual task performance, the most relevant regions are the focus and the immediate surrounding: regions 1 and 2, respectively. With the LMK LabSoft software [6], the average luminance values of each region are calculated. Moreover, using luminance thresholds in relation to the visual task [7,8], glare sources are identified for each image, multiplying the average value of the image by factor 7 .

Table 2. Equipment and software for the visual comfort

\begin{tabular}{|l|l|}
\hline \multicolumn{1}{|c|}{ Sensor } & \multicolumn{1}{c|}{ Model and specifications } \\
\hline $\begin{array}{l}\text { Lux-meter 1 } \\
\text { (indoor) }\end{array}$ & $\begin{array}{l}\text { Digital Illuminance Meter } \\
\text { T-10 Konica Minolta + tripod }\end{array}$ \\
\hline $\begin{array}{l}\text { Lux-meter 2 } \\
\text { (outdoor) }\end{array}$ & $\begin{array}{l}\text { Digital Illuminance Meter } \\
\text { Iso-Tech 1332A }\end{array}$ \\
\hline $\begin{array}{l}\text { Luminance } \\
\text { camera }\end{array}$ & $\begin{array}{l}\text { Video Photo-meter } \\
\text { LMK 98-04 color, TechnoTeam, DXM3466 } \\
\text { with Fish eye lens 180 }, \text { or53324f8sky }+ \\
\text { tripod }\end{array}$ \\
\hline $\begin{array}{l}\text { Digital } \\
\text { photo } \\
\text { camera }\end{array}$ & $\begin{array}{l}\text { Digital Reflex Camera } \\
\text { D-60 Nikon + AF-S Nikkor 18-55mm lens + } \\
\text { fish eye adapter }-180^{\circ}+\text { tripod. }\end{array}$ \\
\hline HDRI & LMK Laboratory Software, TechnoTeam \\
\hline
\end{tabular}

\subsection{Monitoring thermal comfort and air quality: $2^{\text {nd }}$ campaign}

The second monitoring campaign is focused on the thermal comfort and the air quality evaluation during the Mediterranean Games, from June 19th to July 1st of 2018. Two different equipment are used to monitor the environmental variables, as Table 3 and Fig. 4 show. The data has been collected every 3-min, in order to have a detailed evolution of the environmental variables. Additionally, outdoor environmental data have been used to characterize the weather conditions during the monitoring campaign, obtained from a nearby weather station (around $3 \mathrm{~km}$ far).

Table 3 Equipment for the thermal comfort and air quality

\begin{tabular}{|c|c|c|l|}
\hline Equip. & Sensor & $\begin{array}{c}\mathbf{N}^{\mathbf{0}} \\
\text { equip. }\end{array}$ & $\begin{array}{l}\text { Position / } \\
\text { Orientation }\end{array}$ \\
\hline $\begin{array}{c}\text { Sensor } \\
(\mathrm{S})\end{array}$ & Air temperature & 13 & $\begin{array}{l}\text { Court level, } \\
\text { medium and } \\
\text { higher } \\
\text { grandstand/ } \\
\text { All orientations }\end{array}$ \\
\hline Tower & $\begin{array}{c}\text { Air temperature } \\
\text { Relative humidity } \\
\mathrm{CO}_{2} \text { concentration }\end{array}$ & 2 & $\begin{array}{l}1,65 \mathrm{~m} \text { of the } \\
\text { court/ } \\
\text { West and Est }\end{array}$ \\
\hline
\end{tabular}

Using the monitoring data, it is possible to calculate the thermal comfort indexes and the air quality assessment for the audience. The calculated parameters are summarized in Table 4, where the main hypothesis and references are detailed. The operative temperature, the Predicted Mean Vote (PMV), the relative humidity and the Givoni bioclimatic chart are used to characterize the thermal comfort of the audience. Regarding the air quality, the $\mathrm{CO} 2$ concentration has been evaluated.

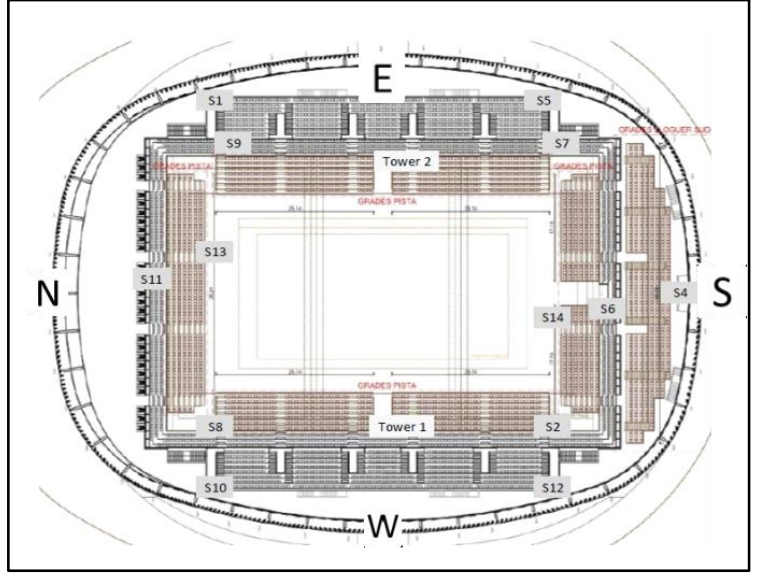

Fig. 4. Drawing of the Catalunya Sports Hall with sensor positions for thermal and air quality measurements.

Table 4. Summary of the calculated comfort indexes

\begin{tabular}{|c|c|c|}
\hline Comfort Index & Hypothesis & Standard \\
\hline $\begin{array}{l}\text { Operative } \\
\text { temperature }\end{array}$ & \multirow[b]{2}{*}{$\begin{array}{l}\text { - Air temperature is equal to } \\
\text { mean radiant temperature } \\
\text { - Air velocity is } 0.1 \mathrm{~m} / \mathrm{s} \\
\text { - Air temperature is equal to } \\
\text { operative temperature } \\
\text { - Metabolic rate of audience } \\
\text { is equal to } 1.2 \text { met } \\
\text {-Clothing of audience is } \\
\text { equal to } 0.5 \text { clo (surveys) } \\
\text { - Only the occupied hours are } \\
\text { considered }\end{array}$} & \multirow[b]{2}{*}{$\begin{array}{c}\text { Fanger } \\
\text { model [9] }\end{array}$} \\
\hline $\begin{array}{l}\text { Predicted Mean } \\
\text { Vote (PMV) }\end{array}$ & & \\
\hline Relative Humidity & - & {$[10]$} \\
\hline $\begin{array}{l}\text { Givoni } \\
\text { bioclimatic chart }\end{array}$ & - & - \\
\hline $\mathrm{CO}_{2}$ concentration & - & {$[10]$} \\
\hline
\end{tabular}

\subsection{Environmental comfort surveys}

The $2^{\text {nd }}$ monitoring campaign has been complemented with 140 environmental comfort surveys to the audience, which have been conducted during the last three days of the Games (June $29^{\text {th }}-$ July $1^{\text {st }}$ ). The main objective is to compare the measured comfort parameters with the perception of the users. The questions of the survey are detailed in Table 5.

Table 5. Questions of the environmental comfort survey

\begin{tabular}{|c|l|}
\hline Comfort & Question \\
\hline Visual & How do you perceive the illumination level? \\
\hline \multirow{4}{*}{ Thermal } & $\begin{array}{l}\text { Which of the following options best indicate } \\
\text { your clothing? }\end{array}$ \\
\cline { 2 - 2 } & How do you asses your thermal sensation? \\
\cline { 2 - 2 } & How do you perceive the humidity level? \\
\cline { 2 - 2 } & How do you perceive the air movement? \\
\hline Air quality & How do you perceive the air (polluted/fresh)? \\
\hline
\end{tabular}

The results are evaluated in two groups, in order to identify possible trends: a) all the surveys together; b) periods with higher/lower occupancy levels. Table 6 
represents the occupancy level for each handball match, highlighting the matches included in the periods with higher and lower occupancy (red and blue, respectively). Additionally, the matches with highest occupancy ( $>500$ people) correspond to the semi-finals and finals competitions, which are televised. For this reason, all the artificial lights are turned on, in order to guarantee an appropriate illuminance level. Fig. 5 shows a picture of two different matches with higher and lower occupancy level.

Table 6. Number of people during the handball matches.

\begin{tabular}{|c|c|c|c|}
\hline Day / Hour & $\mathbf{2 9 / 0 6}$ & $\mathbf{3 0 / 0 6}$ & $\mathbf{0 1 / 0 7}$ \\
\hline $10: 00$ & - & $\mathbf{1 3 5}$ & $\mathbf{9 5 0}$ \\
\hline $12: 30$ & - & $\mathbf{1 8 0}$ & - \\
\hline $13: 00$ & - & - & 600 \\
\hline $17: 30$ & $\mathbf{2 0 0}$ & 380 & - \\
\hline $20: 00$ & $\mathbf{2 0 0}$ & $\mathbf{1 1 5 0}$ & - \\
\hline
\end{tabular}

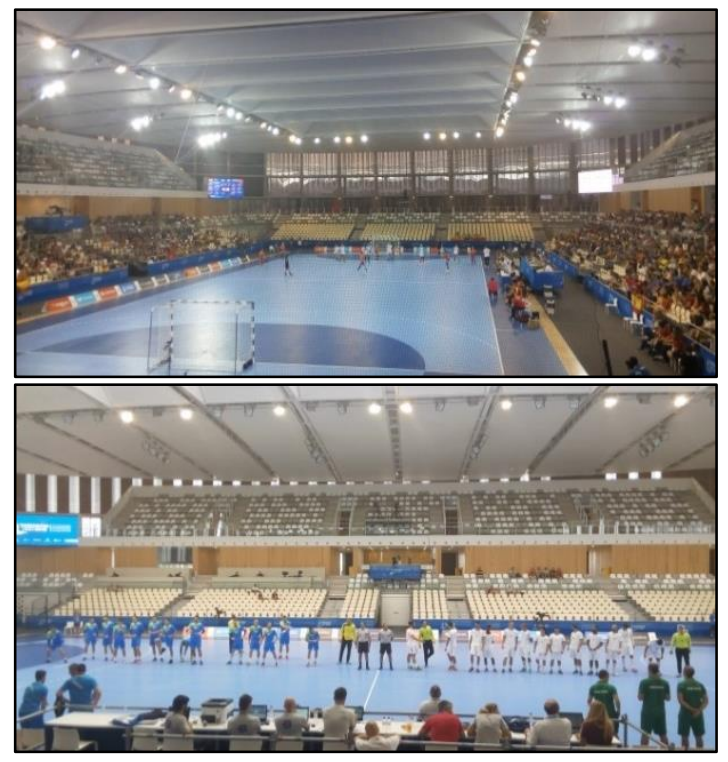

Fig. 5. Handball matches with high and low occupancy levels: 30/06 at 20:00 and 30/06 morning.

\section{Discussion of results}

\subsection{Visual comfort assessment}

The in-situ measurements are taken for specific conditions (sky, time, day and month) and due to the variability of natural light during the day and year [4], the values obtained are given as a reference and cannot be extrapolated to the rest of the year and conditions.

\subsubsection{Horizontal illuminance levels}

The horizontal illuminance level measured on the playing area (Fig. 6), under daylighting conditions, exceeds the minimum for training conditions [11]: 300 $\mathrm{lx}$, as is shown in Table 7 . Also, the $99 \%$ of the points measured on the court have values are over $1000 \mathrm{~lx}$ (from $400 \mathrm{~lx}$ and up to $1000 \mathrm{~lx}$ are the minimum levels for competitions). The horizontal illuminance uniformity
[11] is 0.56 in the central zone of the playing area (red rectangle of $20.0 \times 40.0 \mathrm{~m})$ that accomplishes the minimum required $(\geq 0.50)$.

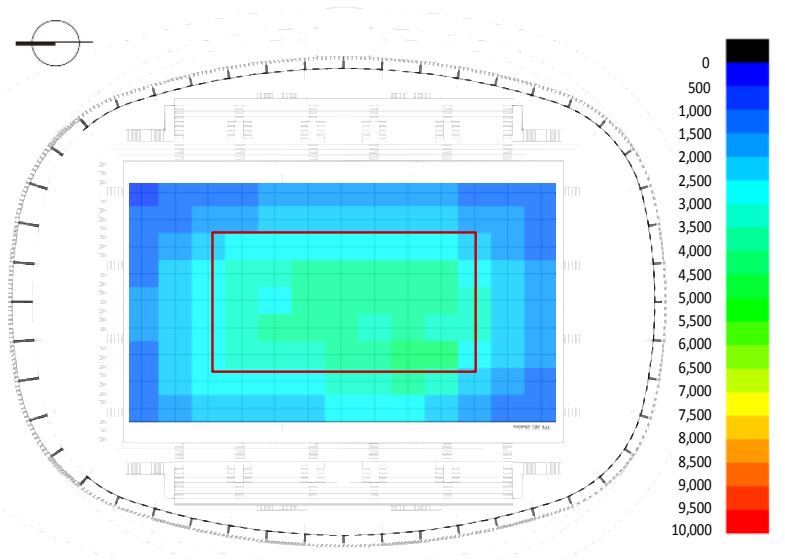

Fig. 6. Drawing of the playing area with the $E_{h}$ measurements results (scale: 0 to $10,000 \mathrm{~lx}$ ) of 27 th of July 2017, outdoor horizontal illuminance: $91,1001 \mathrm{x}-11: 25 \mathrm{~h}$ and 99,800lx $12: 05 \mathrm{~h}$.

Table 7. Horizontal illuminance values and uniformity on the track.

\begin{tabular}{|l|r|}
\hline Horizontal Illuminance & \multicolumn{1}{c|}{ Lux } \\
\hline $\mathrm{E}_{\mathrm{h}} \min$ & 945.00 \\
\hline $\mathrm{E}_{\mathrm{h}} \max$ & $4,188.00$ \\
\hline $\mathrm{E}_{\mathrm{h}}$ average & $2,466.00$ \\
\hline
\end{tabular}

\subsubsection{HDRI and Luminance survey}

The most significant HDR images for the players and the audience are presented below in False colour visualisation. The regions numbered from 4 to 14 have been identified as glare sources (Fig. 7 and Fig. 8). As a summary of the visual comfort assessment for both players and audience, the good distribution of natural light to the playing area has been verified. In this sense, there are no sun patches on the track and glare situations due to the central skylight. Furthermore, the distribution of the luminances on the floor, the ceiling, the side walls and the stands, are generally uniform in the regions 1 and 2 of the FOV. However, some regions have been identified as potential glare sources or that could cause contrast glare (adaptation between 2 surfaces with different luminance values).

- Player point of view:

- the translucent vertical glazing of the North, SouthWest and South orientation, in particular the lower part of the façade (level +0.00 ), mainly when the openings are in the central region of FOV of players (Fig. 7a and Fig. 7c).

- the translucent horizontal glazing of the skylight, but the possibility of glare is less frequent (Fig. $7 \mathrm{~b}$ and Fig. 7c), due to the peripheral position of the skylight in the payers' FOV while they are performing the visual task.

- Audience point of view: 
- the translucent vertical glazing of the lower part of the façade with North and South orientation (level +0.00$)$, particularly when the audience is seating in the North and South tribunes, due to the central position of the windows in the audience's FOV.

- the translucent horizontal glazing of the skylight, specially form West and Est seating area (Fig. 8), due to the near surrounding position of the skylight in the audience's FOV.
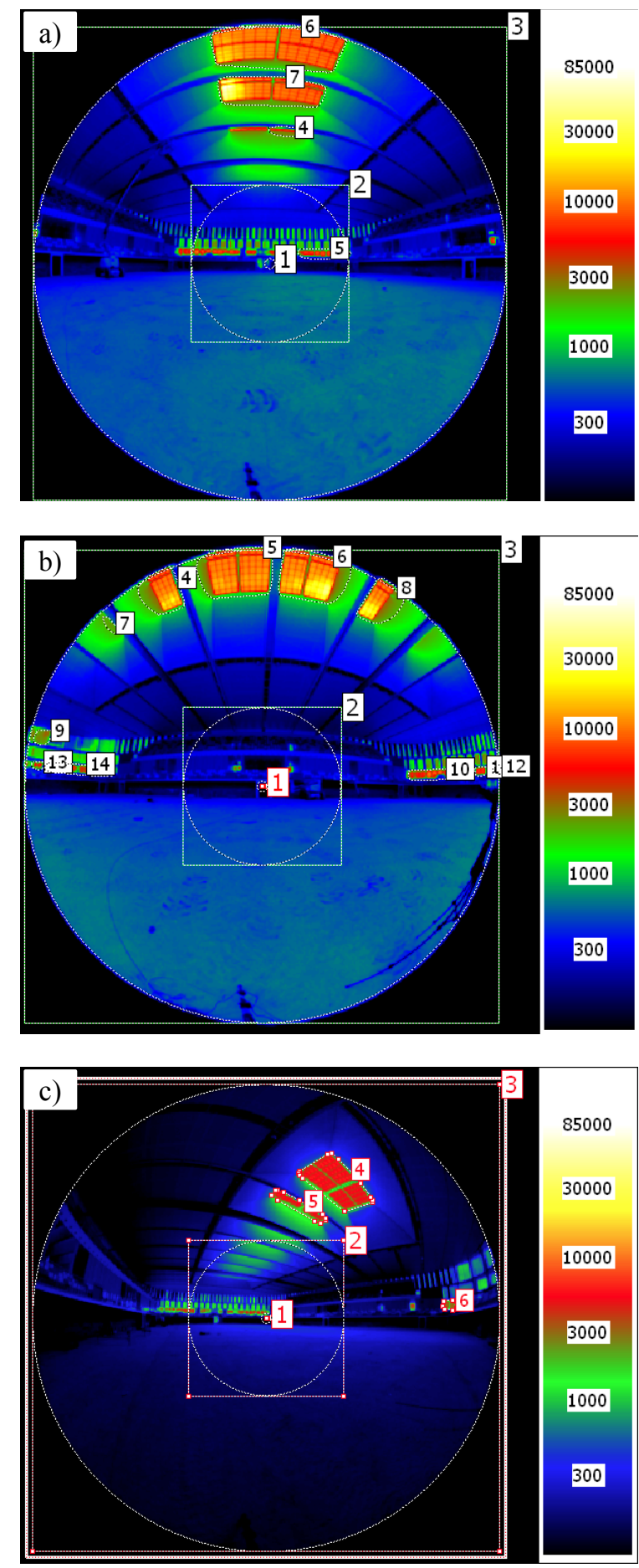

Fig. 7. HDR Image with False colour visualisation from players' point of view. a) Player view point 1-towards South; b) Player view point 2- towards Est; c) Player view point 6towards South-West

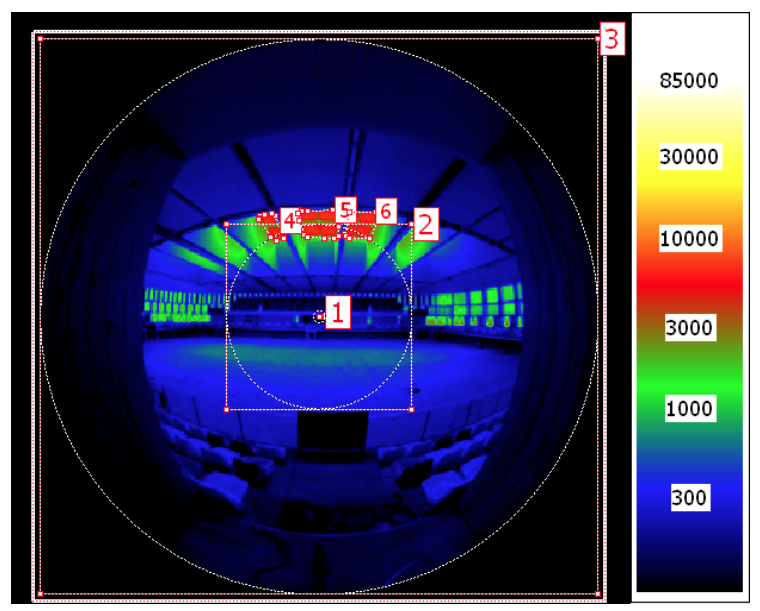

Fig. 8. HDR image from audience view point 8- towards West.

\subsubsection{Visual comfort survey}

Analysing the results of all the surveys responses suggest that, in general, the visual comfort is achieved for the majority of the audience (Fig. 9), as the overall illumination provided is considered as "Neutral" by the $64 \%$, followed by a $30 \%$ that considers the lighting level is "Slightly intense".

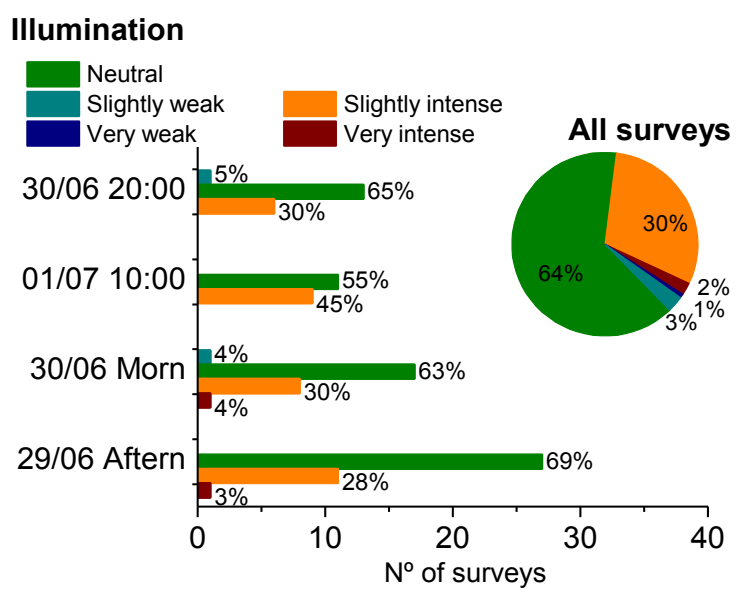

Fig. 9. Results of the visual comfort question for the whole surveys and the matches with higher and lower occupancy levels (Higher: 30/06 at 20:00 and 01/07 at 10:00; Lower: 30/06 Morning and 29/06 Afternoon)

The trend of responses in the different periods of the day (morning, afternoon) is the same, with the exception of the slot on $01 / 07$ at $10: 00 \mathrm{~h}$, where the "Neutral" perception decreases up to $55 \%$ and the "Slightly intense" increases to $45 \%$. The match played on $01 / 07$ at 10:00 was the handball final competition and was televised. All the televised matches have the total of artificial lights turned on, in order to guarantee suitable conditions for TV broadcasting, with maximum lighting levels on the court. That situation could explain the increasing of "Slightly intense" illumination level perception by the audience, due to high levels of both: artificial and natural lighting (10:00 of the morning, with a clear sky). 


\subsection{Thermal comfort and air quality assessment}

The outdoor conditions during the monitoring campaign presented maximum temperatures around $26-28^{\circ} \mathrm{C}$ and minimum temperatures around $20^{\circ} \mathrm{C}$. The relative humidity was higher than $50 \%$ during the day, and increased up to $80 \%$ during the night. In terms of solar radiation, most of the days were clear sky achieving maximum values around $1000 \mathrm{~W} / \mathrm{m}^{2}$ of total solar radiation. The weather conditions of those days would provide a thermal sensation quite hot.

The analysis is focused on the monitoring data of the Tower equipment, which cover the thermal comfort and the air quality evaluation of the main area where the audience was located (court level and medium grandstand).

\subsubsection{Thermal comfort and air quality indexes}

Four different parameters are used to evaluate the thermal comfort. Fig. 10 represents the air temperature, which is assumed to be equivalent to the operative temperature, and the relative humidity. In both graphs, the thresholds of each comfort Category are established, being the Category I the more demanding. Following the definition of each Category, the sport hall should operate within the Category II: Minimum comfort category recommended for new or retrofitted buildings.
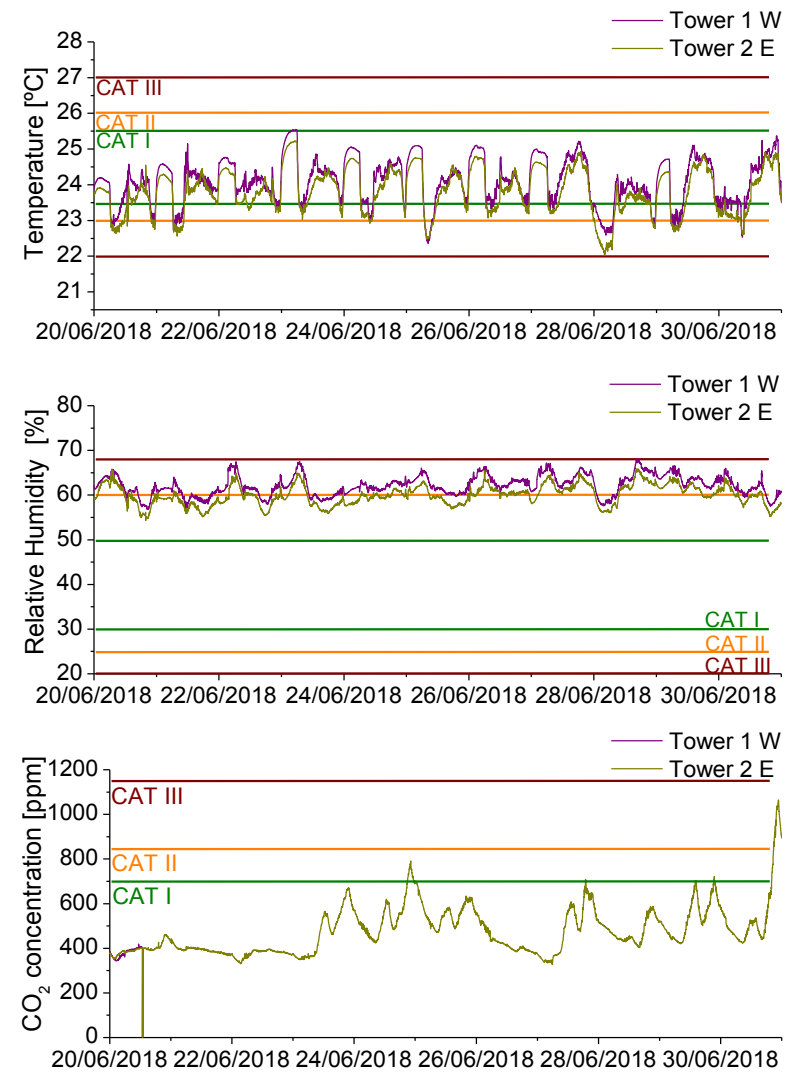

Fig. 10. Thermal comfort and air quality monitored during the Mediterranean Games in relation to their corresponding comfort Categories: Air temperature, Relative humidity and $\mathrm{CO}_{2}$ concentration

The air temperature is most of the time within the comfort Category II. However, in some few periods, the temperatures are below the lower threshold of Category II. In all the cases, the colder periods correspond to the time where the HVAC system is switch-on (around $6: 30 \mathrm{~h}$ in the morning), when there is not occupancy in the building. The difference between both towers is lower than $0.5^{\circ} \mathrm{C}$ and can be due to the location of the sensors. The relative humidity is most of the time between $50-70 \%$, which corresponds to the comfort Category III. In general, the relative humidity increases during the night hours and the HAVC system should dehumidify the air during the day time. This behaviour is typical from coastal areas due to the effect of the sea breeze.

Fig. 11 represents the percentage of time with occupancy where the PMV is in each comfort Category. The three different Categories are represented (I, II and III), together with the sign of the PMV: negative means cool and positive means warm. The results show that for both Towers, most of the time the PMV is in Category I and II. However, some differences can be observed between the towers: Tower $1-\mathrm{W}$, located in the West grandstand, is in Category I around $85 \%$ of the time and around $15 \%$ in Category II, being the distribution between PMV $>0$ and PMV $>0$ quite similar; the Tower 2-E, located in the Est grandstand, presents a lower fraction of Category I, and consequently a higher fraction of the Category II, being the PMV $<0$ the more predominant (around $75 \%$ of the time the $\mathrm{PMV}<0$ ). Therefore, in general the PMV is within the comfort Category II, however the Est grandstand presents cooler conditions than the West grandstand.

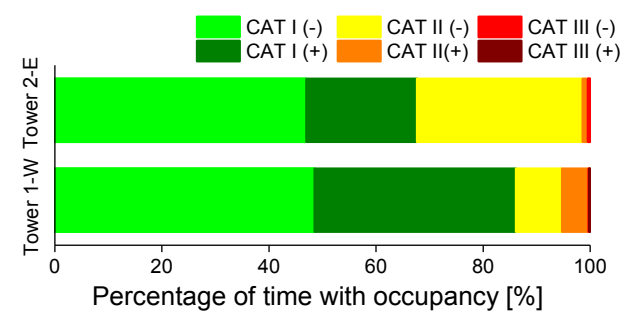

Fig. 11. Percentage of time where the PMV is in each comfort Category. It is differentiated the Category I, II and III; and the sign of the PMV (positive: warm, negative: cool)

Finally, Fig. 12 represents the Givoni bioclimatic chart with the outdoor and the indoor (tower 2-E) temperature and relative humidity plotted. The diagram represents the comfort zone in green, and it is possible to observe that all the indoor values (red) are inside the zone. Most of the outdoor conditions are in the Cooling Dehumidifying Zone and the building design and its HVAC system are able to provide comfortable indoor conditions. The air quality assessment is done evaluating the $\mathrm{CO} 2$ concentration. The last graph of the Fig. 10 represents $\mathrm{CO} 2$ values registered by the towers. During most of the time, the $\mathrm{CO} 2$ concentration is within the Category I, with an exception of the last period of monitoring. At that moment, there was the award ceremony and the $\mathrm{CO} 2$ sensor location was close to the main entrance to the court, where all the people were concentrated. For that reason, the $\mathrm{CO} 2$ increases up to Category III. 


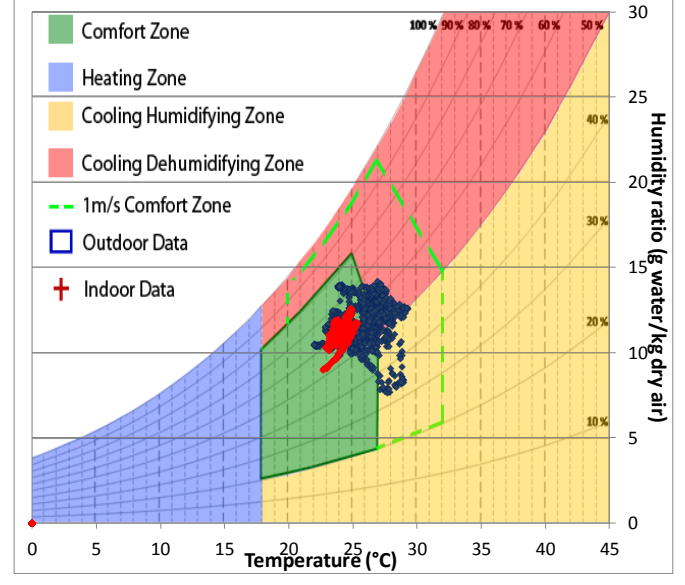

Fig. 12 Givoni bioclimatic chart representing the outdoor conditions (blue) and the indoor conditions of the Tower 2-E (red) during occupied time $(10: 00 \mathrm{~h}-22: 00 \mathrm{~h})$

\subsubsection{Thermal comfort and air quality survey}

The thermal comfort and air quality evaluation is complemented with the results of the environmental comfort surveys. Fig. 14 and Fig. 14 represent the main results in terms of thermal comfort and air quality, respectively.

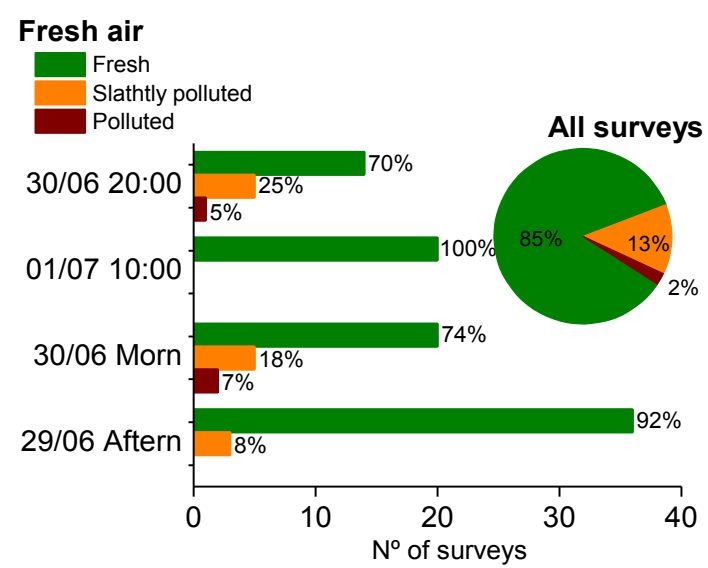

Fig. 13. Results of the air quality question for the whole surveys and the matches with higher and lower occupancy levels (Higher: 30/06 at 20:00 and 01/07 at 10:00; Lower: 30/06 Morning and 29/06 Afternoon)

In general, the answers demonstrate that the audience feel as "neutral" in relation to the thermal sensation, the relative humidity, the air movement and the fresh air, being the most frequent answer (58-85\%). In general, the patterns observed analysing all the surveys are the same than by periods, with some particularities:

- The most frequent answer of thermal sensation during the period 30/06 Morning, which correspond to a low occupancy period, is "Slightly cool" with $37 \%$, followed by "Neutral" with $33 \%$. The causes of this slight discomfort could be a combination of effects: the low level of occupancy and the hour of the day, when the lower temperatures were registered.

- The most frequent answer in relation to the relative humidity level is "Neutral"; however, the second answer varies depending on the hour of the day: the surveys collected during the morning, around $30 \%$ of the answers are "slightly wet", since during the afternoon around $30 \%$ are "slightly dry". This perception could be related to the outdoor condition behaviour (higher relative humidity at night).

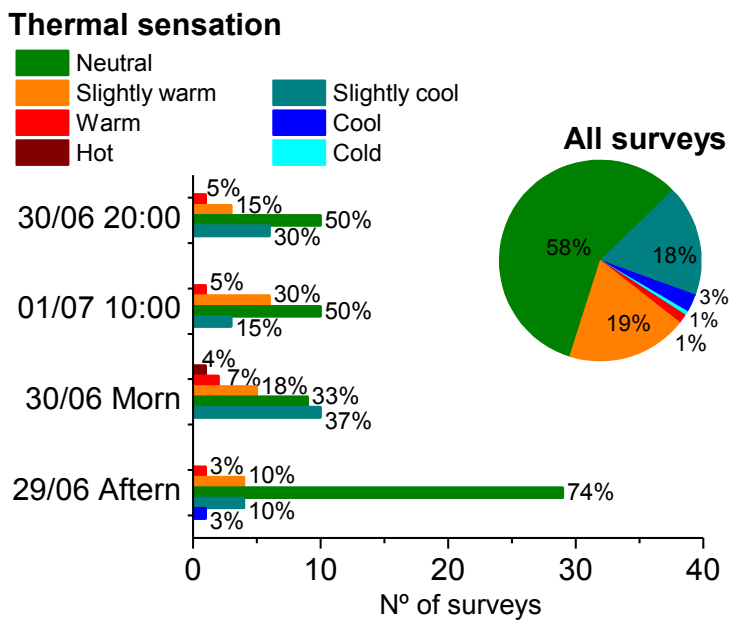

\section{Relative Humidity}
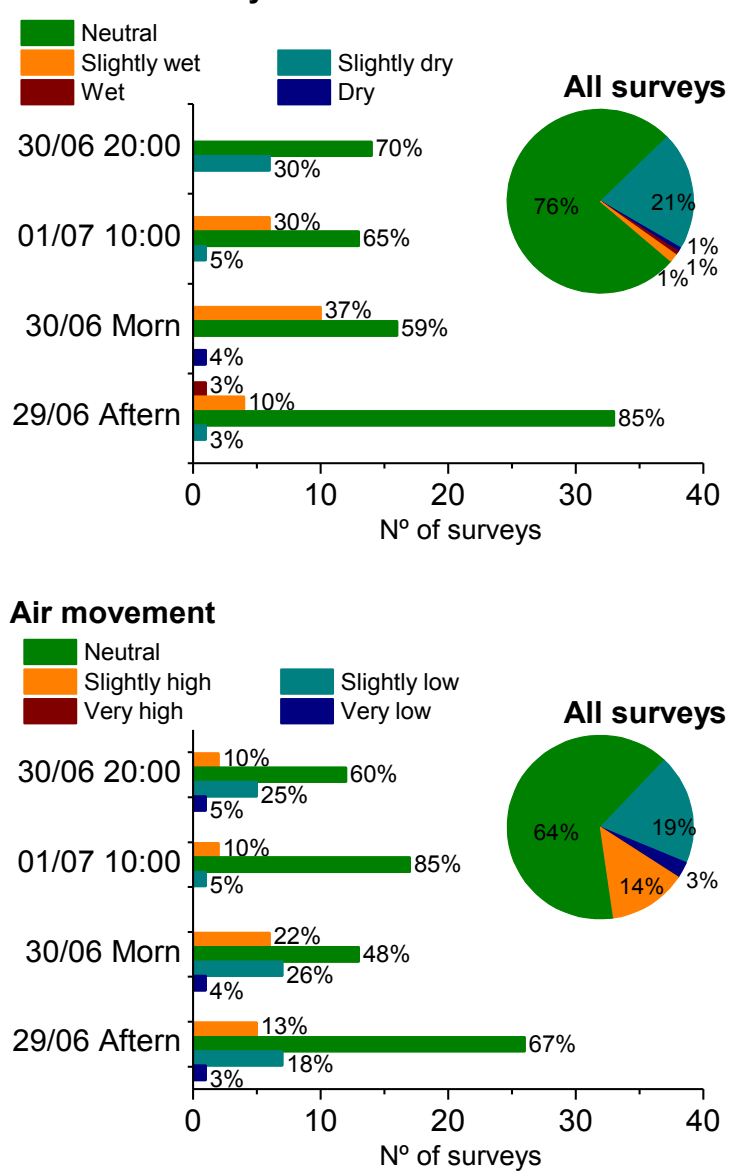

Fig. 14. Results of the thermal comfort questions for the whole surveys and the matches with higher and lower occupancy levels (Higher: 30/06 at 20:00 and 01/07 at 10:00; Lower: 30/06 Morning and 29/06 Afternoon) 


\section{Conclusions}

The work presented in that paper is focused on a PostOccupancy Evaluation of a nZEB sport Hall, which has been performed based on two monitoring campaigns. The assessment is divided in three main environmental comfort analyses: visual comfort, thermal comfort and air quality. The monitoring campaigns are complemented with an environmental comfort survey to the audience, in order to correlate the monitored data to the user perception.

The results of the detailed visual comfort assessment under daylight conditions show the complexity of the visual environment evaluation in this type of buildings. For that, multi-directional viewpoints and different visual user requirements and user positions onto the space have been considered. Although the measurements and the HDR images are taken under specific conditions (sky, time, day and month); the results validate the integrated measures into the early phases of the design project by the daylight optimization of the central skylight for the visual comfort. Likewise, the good performance of the skylight is demonstrated during a period of maximum values of global solar radiation (summer), avoiding direct light and sun patches on the court. The audience surveys show that the visual comfort is achieved during the international competitions, under both natural and artificial lighting. Importantly, visual comfort conditions are also accomplished during daytime for the specific requirements of TV transmission of the Mediterranean Games, with a high contribution of the natural light.

In relation to the thermal comfort results, the evaluated indexes demonstrate that the building and its HVAC system are able to provide high levels of thermal comfort to the users, being in most of the cases in Category I and Category II of comfort. The only exception is the relative humidity, which is most of the time in Category III. However, analysing the Givoni bioclimatic chart, the relation between the indoor temperature and the relative humidity are inside the thermal comfort zone. Comparing those results with the surveys, the audience feels neutral conditions for thermal sensation, relative humidity and air movement. Therefore, there is coherence between the monitored parameters and the answers of the occupants.

The air quality assessment demonstrate that the $\mathrm{CO} 2$ concentration levels are in Category I for most of the time, fact that is confirmed with the survey's results.

Some trends have been observed (the air temperature is close to the lower comfort threshold during the first hours of the day, the relative humidity is higher in the morning, the Est grandstand are colder than the West grandstand) and need to be followed with especial attention in order to avoid possible discomfort situations in the future. Additionally, further research is needed to complement the study with: the energy evaluation of the building, in order to verify the nZEB energy objectives; the behaviour of the building under different weather conditions (winter) and higher levels of occupancy.

Concluding, the design of the nZEB sport hall achieves the main objectives related to provide comfortable conditions to the users. Additionally, it is demonstrated the importance to perform specific studies before and after the building construction, in order to evaluate the environmental comfort of the users.

Acknowledgements: This work was supported by the Consell Català de l'Esport, Generalitat de Catalunya.

\section{References}

1. European Comission, Energy Performance of Building Directive (EPBD). 2010/31/EU (2010)

2. M.L. González Matterson, J. Salom. Simulacions dinàmiques de llum natural $i$ anàlisi dels tancaments pel projecte: Nova construcció del Palau d'Esports a la zona esportiva del Camp Clar de Tarragona, (Institut de Recerca en Energia de Catalunya - IREC, 2015)

3. M.L. González Matterson, J. Ortiz, J. Salom. Mesures d'il-luminància horitzontal $i$ aixecament HDRI al Nou Palau d'Esports a la zona esportiva del Camp Clar de Tarragona. (Institut de Recerca en Energia de Catalunya - IREC, 2017)

4. M.C. Dubois, N. Gentile, C.N.D. Amorim, D. Geisler-Moroder, R. Jakobiak, B. Matusiak, S. Stoffer, S. Monitoring Protocol for Lighting and Daylighting Retrofits. (Technical Report of IEA SHC Task 50: Fraunhofer-Institut für Bauphysik, 2016)

5. M. Inanici, Lighting Res Technol 38, 123-136 (2006)

6. T. Porsch, F. Schmidt, The $2^{\text {nd }}$ CIE Expert Symposium (2010)

7. J. Wienold, J. Christoffersen, Energ Buildings 38, 743- 757 (2006)

8. J. Wienold, Daylight Glare analysis and metrics, (Radiance Workshop, 2014)

9. UNE-ISO 7730:2006. Ergonomics of the thermal environment - Analytical determination and interpretation of thermal comfort using calculation of the PMV and PPD indices and local thermal comfort criteria (2006)

10. UNE-EN 15251:2008. Parámetros del ambiente interior a considerar para el diseño y evaluación de la eficiencia energética de edificios incluyendo la calidad del aire, condiciones térmicas, iluminación $y$ ruido (2008)

11. UNE-EN 12193:1999. Iluminación. Iluminación de instalaciones deportivas (1999) 